\title{
Performance Profile of Kayaker Team Indonesia
}

\author{
Syahid Nur Yasin ${ }^{1,2}$ \\ ${ }^{1}$ Prodi Pendidikan Olahraga, Sekolah Pascasarjana \\ 2 Pendidikan Jasmani Kesehatan dan Rekreasi \\ ${ }^{1}$ Universitas Pendidikan Indonesia, ${ }^{2}$ STKIP Pasundan \\ ${ }^{1}$ Bandung, ${ }^{2}$ Cimahi, ${ }^{1,2}$ Indonesia \\ syahid_bandung@yahoo.co.id
}

\author{
Amung Ma'mun, Agus Rusdiana \\ Prodi Pendidikan Olahraga, Sekolah Pascasarjana \\ Universitas Pendidikan Indonesia \\ Bandung, Indonesia \\ amungmamun@upi.edu, agus.rusdiana@upi.edu
}

\begin{abstract}
The purpose of this research is to know the fitness level of physical condition of athletes National Kayak Kayak Indonesia. The sample in this study is the national athlete of the son of Indonesian rowing totaling 19 people with the average age of 25 years, 175 height and body weight 74 . The method in this study uses a qualitative descriptive method. Qualitative descriptive research is a research method based on the post positivism philosophy that is commonly used to examine the natural objective conditions in which researchers act as key instruments. The research method used a survey with the approach of the Canoeing Protocol Test and TBR National Team. The results of this study showed that the endurance test speed with a single Kayak speed of 1000 meters in water obtained $85 \%$ average value and $95 \%$ good, maximum strength test and maximum resistance of chest and shoulder muscles obtained $75 \%$ average and $100 \%$ good, heart resistance, blood circulation and breathing with a 12 minute run showed good value. From the above average test results are known to have a good score of 2 tests, 1 test with $50 \%$ moderate and $50 \%$ good, 1 test with $40 \%$ good and $60 \%$ very good, and good value there is 1 test. From the results of the five test components of the Test Canoeing and TBR protocols can be taken on average that the fitness level of physical condition of the National Kayak Kayak athlete Team Indonesia is good category.
\end{abstract}

Keywords—canoeing; fitness; athletes; kayaking

\section{INTRODUCTION}

Canoeing is an Olympic sport that is divided into two disciplines: canoe $(\mathrm{C})$, where the athlete pedals on one side while kneeling on one knee, and like (K), where the athlete paddles on both left and right sides in a sitting position. This is a sport where athletes compete to complete linear lines $(1,000 \mathrm{~m}, 500 \mathrm{~m}, 200 \mathrm{~m})$ in the fastest, non-flowing water [1]. The Olympic type Canoeing type consists of Kayak and Canoe and has been recognized by the international body namely ICF [2].

Physical development by exercising regularly can affect a person's health both physically and spiritually [3]. Physical fitness is a person's ability to perform tasks that require effort in everyday life efficiently without experiencing significant fatigue [4].

The appearance of an athlete can be seen from the competition he followed by looking at the main elements of physical performance. One that has been studied is from the research of Suzukawa and his colleagues that is to compare and investigate the relationship between physical characteristics and fitness between two competitors. Like a sprint [1].

Fitness factors can affect an athlete's achievement, this is also included in Kayaking, where this sport is very demanding a good level of fitness for an athlete can finish each match well too [5].

Sports Achievements These things are in desperate need of maturity in the race, because more mature rowers are also those who reveal the greatest body size, level of physical fitness and best rowing performance [6]. In addition, the most important variables that predict performance time in kayaking are maturity status and chronological age [7]. This exercise is very close to the exercise of muscle strength and endurance, as well as swimming sports [8]. The athlete's level of fitness can influence the level of endurance of the athlete's speed in competing. Based on this background, the researcher wants to know the profile of the athlete's fitness condition like Indonesia.

\section{METHOD}

\section{A. Research Design}

The method in this study uses a qualitative descriptive method. Qualitative descriptive research is a research method based on the post positivism philosophy that is commonly used to examine the natural objective conditions in which researchers act as key instruments. Population of the study In this study the population was 19 athletes from the Indonesian National Canoeing Sample research in this study the authors used the sample saturated sample saturation is a sample determination technique when all members of the population are used as samples. This is often used if the population is relatively small at less than 30 people. The saturated sample term is a census, where all population members are sampled.

\section{B. Participants}

The population and sample used as subjects in this study were 19 athletes. The data obtained consisted of 5 test items, namely the maximum endurance bench pull for measuring the local muscular endurance of the arm and upper back body, the maximum endurance bench press for measuring the local muscular endurance of the arm and the front upper body, the maximum srtrength bench pull for measures the local muscle strength of the arms and upper upper body, the maximum 
strength bench press to measure local arm and upper body muscle strength, and VO2Max to measure cardioascular endurance. From each of these tests then the data is converted to the norms of the physical condition category which is perfect, excellent, good, sufficient, and lacking.

\section{Instrument}

Finally, The results showed that the overall physical condition of the Indonesian Canoeing Number Paddle National Team was in the Good category. This is shown from several test items that do not get maximum results. The table shows the physical condition in a good category with a conversion value of 6. Judging from the above components, it can be seen that the VO2Max and Endurance Bench Press components get the perfect score, therefore with good training and good time it is expected to remain stable and not show a decrease in these components. In the Endurance component the Bench Pull gets good results, but it will be better if it is upgraded so that it can support the competition during the match. Whereas for the Bench Pull Strength and Strength Bench Press components get less results, therefore this component must be improved considering that Paddle sports are sports that are in dire need of very good strength. The average results of the VO2Max test were 58.24 in the perfect category, Endurance Bench. Pull the average acquisition of 75.79 in the good category, Endurance Bench Press, the average acquisition was 82.84 in the perfect category, Strength Bench Pull, the average acquisition was 119.6 with the poor category, and Strength Bench. Average acquisition of 132.8 with good category.

Furthermore, to find out the percentage of categories for each physical component from a sample of 19 athletes, it will be shown in the VO2Max component table of 19 athletes Indonesian National Team.

TABLE I. PERCENTAGE OF CATEGORIES OF EACH COMPONENT PHYSICAL CONDITION

\begin{tabular}{|l|l|l|l|l|l|l|}
\hline \multirow{2}{*}{$\begin{array}{c}\text { Physical } \\
\text { components }\end{array}$} & \multicolumn{6}{|c|}{ Percentage of Category } \\
\cline { 2 - 7 } & Perfect & $\begin{array}{c}\text { Very } \\
\text { good }\end{array}$ & Good & Fair & Less & $\begin{array}{c}\text { Very } \\
\text { Less }\end{array}$ \\
\hline VO2 Max & $37 \%$ & $32 \%$ & $5 \%$ & $10 \%$ & $0 \%$ & $16 \%$ \\
\hline $\begin{array}{l}\text { Endurance } \\
\text { Bench pull }\end{array}$ & $16 \%$ & $16 \%$ & $53 \%$ & $5 \%$ & $10 \%$ & $0 \%$ \\
\hline $\begin{array}{l}\text { Endurance } \\
\text { Bench Press }\end{array}$ & $58 \%$ & $16 \%$ & $11 \%$ & $0 \%$ & $5 \%$ & $10 \%$ \\
\hline $\begin{array}{l}\text { Strength } \\
\text { Bench Pull }\end{array}$ & $0 \%$ & $0 \%$ & $0 \%$ & $5 \%$ & $47,5 \%$ & $47,5 \%$ \\
\hline $\begin{array}{l}\text { Strength } \\
\text { Bench Press }\end{array}$ & $0 \%$ & $5 \%$ & $5 \%$ & $21 \%$ & $16 \%$ & $53 \%$ \\
\hline
\end{tabular}

1) Test of aerobic components (VO2Max): In the physical condition component test, VO2Max shows that the average test score has an excellent category of $90 \%$, this shows that aerobic (VO2Max) possessed by Indonesian Rowing athletes is in excellent condition.

2) Endurance bench pull test: It appears that the average percentage of endurance bench pull test shows a good category of $80 \%$, this shows that the endurance bench pull owned by Indonesian rowing athletes is in good condition.

3) Test of muscle endurance components (endurance bench press): In this component test showed an average acquisition of $100 \%$, this shows that the endurance bench press of Indonesian rowing athletes is perfect. This is very supportive in its performance, because rowing is included in the strength endurance category.

4) Component strength test (strength maximum bench pull): In the component test Strength Maximum Bench Pull shows an average gain of $40 \%$. This shows that the maximum Bench Pull strength of Indonesian rowing athletes is less. This is very worrying because considering the Indonesian Canoeing Paddle Team is a reflection of the quality of the athlete itself. This is an evaluation material for coaches in the future to develop training programs for athletes so that their physical condition increases, especially the maximum strength of the bench pull.

5) Component test for local muscle strength (strength maximum bench press): In the component test the Maximum Strength Bench Press shows an average gain of $60 \%$. This shows that the maximum Bench Pull strength of Indonesian rowing athletes is lacking. This is very worrying because considering the Indonesian Canoeing Paddle Team is a reflection of the quality of the athlete itself. This is an evaluation material for coaches in the future to develop training programs for athletes so that their physical condition increases, especially the maximum strength of the bench pull.

TABLE II. Test RESUlts AND TARGET PERCENTAGE

\begin{tabular}{|c|l|c|c|c|c|}
\hline No. & Test & $\begin{array}{c}\text { Test } \\
\text { protocol }\end{array}$ & Percentage & $\begin{array}{c}\text { Test } \\
\text { average }\end{array}$ & $\begin{array}{c}\text { Percentag } \\
\text { e }\end{array}$ \\
\hline 1 & VO2 Max & 60 & 100 & 58,24 & 90 \\
\hline 2 & $\begin{array}{l}\text { Endurance } \\
\text { Bench pull }\end{array}$ & 80 & 100 & 75,79 & 80 \\
\hline 3 & $\begin{array}{l}\text { Endurance } \\
\text { Bench Press }\end{array}$ & 80 & 100 & 82,84 & 100 \\
\hline 4 & $\begin{array}{l}\text { Strength } \\
\text { Bench Pull }\end{array}$ & 160 & 100 & 119,6 & 40 \\
\hline 5 & $\begin{array}{l}\text { Strength } \\
\text { Bench Press }\end{array}$ & 170 & 100 & 132,8 & 60 \\
\hline
\end{tabular}




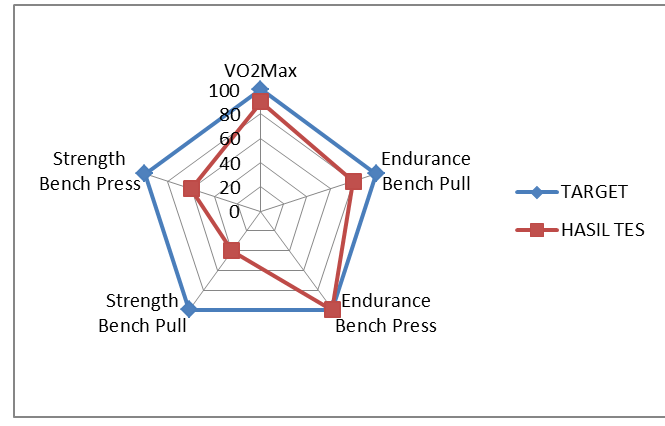

Fig. 1. Percentage of overall categories of tests.

\section{RESULTS AND DISCUSSION}

Preparation of physical conditions is one that must be considered and considered from several important cases as elements that are needed in training to reach the peak of performance or achievement [6]. From the description of research results obtained that Level of Physical Conditions The Indonesian Paddle National Team on National Selection is in the perfect category with the highest average percentage of physical components, namely 19 athletes with a percentage of $90 \%$ of the 19 Indonesian Rowing National Team athletes. The level of physical condition of the Indonesian Paddle National Team in perfect category is $80 \%$ of people or $80 \%$ of excellent category as much as 2 people or $100 \%$ good category as many as 19 people or $90 \%$ enough categories as much as 0 or $0 \%$ and less categories as much as 0 or $0 \%$. Based on the results of the study shows that the physical condition of the Indonesian Paddle National Team at the Asia Oceania Paddle Championship. National selection is in a good category, and must be improved so that the physical condition is perfect for the performance during the match.

With the added portion of the exercise like a well-made program and interval training in each exercise will improve the physical condition of the athlete, not only that the exercise program that is made well will affect whether or not the physical condition of a player is improved. The coach is a training program plan that is strong for every aspect of the exercise and physical components. Physical conditions are one of the prerequisites that are very necessary in an athlete's effort to increase, even as a basis for the starting point of an achievement sport. High achievement of an athlete will depend on the abilities and physical conditions that are owned. This shows that physical conditions will be a factor that has a major influence on the athlete's achievements. A well-controlled and well-controlled training program will be able to.

\section{CONCLUSION}

Based on the results of data processing and data analysis, the researchers concluded that the physical condition of the Canoeing rowing national team in the National Selection was in the good category with the following results:

- Physical Components of 90\% VO2Max, Very Good Category.

- Physical Components of Endurance Pull Bench (80\%) Good Category.

- Physical Components Endurance Press Bench 100\%, Perfect Category.

- Physical Components Bench Strength Pull 40\% in Very Less Category.

- Physical Components Strength Bench Press Strength $60 \%$ in the Less category

With the acquisition of an average percentage of all physical components, as many as 19 athletes or $100 \%$ of the 19 athletes of the Indonesian Paddle National Team.

\section{REFERENCES}

[1] K. Suzukawa, Relationship between performance test and body composition / physical strength characteristic in sprint canoe and kayak paddlers, pp. 191-199, 2015.

[2] Manual Book, CANOE SPRINT COACHING MANUAL

[3] J.S. Michael, K.B. Rooney, and R.M. Smith, The dynamics of elite paddling on a kayak simulator The dynamics of elite paddling on a kayak simulator, pp. 37-41, 2012.

[4] J.S. Michael, K.B. Rooney, and R. Smith, The metabolic demands of kayaking, pp. 37-41, 2012.

[5] M.A. Opondo and S. Sarma, "The Cardiovascular Physiology of Sports and Exercise," CSM vol. 34, no. 3, pp. 391-404, 2015.

[6] O. Tudor, T. Bompa, and C. Buzzichelli, Periodization Training for Sports.

[7] D. López-plaza, F. Alacid, J.M. Muyor, and P.A. López-miñarro, Differences in Anthropometry , Biological Age and Physical Fitness Between Young Elite Kayakers and Canoeists, vol. 57, pp. 181-190, 2017.

[8] D. López-Plaza, F. Alacid, J.M. Muyor, and P.A. López-Miñarro," Sprint kayaking and canoeing performance prediction based on the relationship between maturity status, anthropometry and physical fitness in young elite paddlers," J Sports Sci., vol. 35, no. 11, pp. 1083-1090, 2017 